\title{
FORMAÇÃO TERRITORIAL DO CEARÁ: DOS CAMINHOS ANTIGOS AOS PROJETOS FERROVIÁRIOS (1817-1877)
}

\author{
TERRITORIAL FORMATION OF CEARÁ: FROM THE OLD ROADS \\ TO RAIL PROJECTS (1817-1877)
FORMATION TERRITORIALE DU CEARA: ENTRE LES VOIES DE BOVINS ET LES DEMANDES DES CHEMINS DE FER (1817-1877) \\ Raimundo Jucier Sousa de Assis - Universidade Estadual do Ceará - Limoeiro do Norte - Ceará - Brasil \\ raimundojucier@usp.br \\ José Levi Furtado Sampaio - Universidade Federal do Ceará - Fortaleza - Ceará - Brasil \\ joselevi@uol.com.br
}

\section{Resumo}

0 estudo trata do processo de formação territorial do Ceará, ocorrido entre 1817 a 1877 . A análise tem como aporte investigativo a identificação dos processos político-econômicos que grafaram os caminhos do gado e, posteriormente, as pretensões por estradas de ferro nessa província. A especificidade do escrito está em apresentar a produção da geografia material como uma possibilidade de leitura das transformações da vida social nos territórios.

Palavras-chave: território, periferia, estradas, Ceará.

\section{Abstract}

The study talks about the process of territorial formation of Ceara in the years 1817 and 1877 . The analysis takes as input the identification of investigative processes that spelled the ways of cattle and later claims by railways in this province. The specificity of the writing is to present the material production of Ceara geography as a possible reading of the changes in territories social life.

Keywords: territory, periphery, paths, Ceara.

\section{Résumé}

C'est étude examine les processus de formation territoriale du Ceará dans le periode 1817 - 1877. Le sujet de cet analyse c'est identifier des processus politiques et économiques que ont structuré les voies de bovins et, postérieurement, les demandes des chemins de fer dans cette province. La spécificité de cet étude est présenter des recherches de la géographie matérielle comme une possibillité de comprendre les transformations de la vie sociale dans les territoires.

Mots clés: territoire, périphérie, route, Ceará.

\section{Introdução}

Como nos ensina Evaldo Cabral de Mello (1999), no começo só tínhamos "duas regiões” oficiais no Brasil: a região Norte e a região Sul. Aparentemente, uma demarcação mais simples para resolver os problemas políticos ditos da metrópole ou imperiais, mas, economicamente, uma 
delimitação geográfica desigual e contraditória. No interior e nas relações com o entorno de cada província era que se tinha o controle do território e dos recursos, natural e "populacional", que estavam sob as decisões de alguns homens proprietários de terra-escravo, homens de política, donos de boiadas, estradas, embarcações, lavouras e das construções urbanas, relações travadas por rivalidades entre vizinhos, famílias e partidos políticos de distintas localizações internas, no interior das regiões e no trato com a Corte.

Tomando como referência o conceito de região de Ilmar de Mattos (1999), que explica essa formação social territorial-fragmentada do Brasil entre as oligarquias locais-regionais, territórios provinciais circunscritos e especificidades em sua ocupação, cabe aqui esclarecer um pouco do que passa a ser compreendido como Ceará no oitocentos da monarquia no Brasil.

No conjunto da região Norte, a formação territorial do Ceará teve como vínculo político, econômico e cultural inseparável as províncias da Paraíba, do Piauí, do Rio Grande do Norte e principalmente de Pernambuco. ${ }^{1}$ Esta última era o centro açucareiro-econômico, político, escravista e "intelectual" da região, aparecendo na hierarquia das províncias do Norte, denominadas Norte Agrário, interpretação elaborada por Evaldo Cabral de Mello (1999). ${ }^{2}$

De acordo com o princípio de gênese no interior de uma "região de agricultura mercantil-escravista” (Mattos, 1999), o Ceará, socialmente, foi constituindo-se como peculiaridade econômica e de homens políticos envolvidos com as atividades de subsistência, principalmente a criação de gado, o comércio de peles e de carnes secas (charques). A produção agrícola era baseada na cultura do milho, do feijão, da mandioca, na extração da cera da carnaúba, na produção de algodão, café e no plantio de cana para a produção de rapadura.

Formaram-se, no conjunto dessas especificações, redes de comércio que tiveram como objetivo abastecer o mercado interno provincial, a região Norte e até o Sul do Império. Porém, o grande destino de sua produção e das comunicações estava a caminho das zonas de concentração da terra de proprietários escravistas, como era o caso Zona da Mata Pernambucana. ${ }^{3}$

Essa especificação do povoamento dominante europeu e da ocupação do Ceará com a atividade pecuária e com a agricultura de subsistência 
tem significativa expansão geográfica somente ao longo do século XVIII. ${ }^{4}$ Essa expansão ocorreu, de um lado, com as ocupações nas margens dos rios e dos valles do Salgado, Acaraú, Banabuiú, Coreaú, Mundaú e, principalmente, Jaguaribe, por boiadeiros-boiadas, e de outro, por motivos de uma tardia cartografia colonial, elaborada apenas nos últimos anos das colonizações portuguesas no Ceará da América. Poderíamos dizer ainda que tanto a ocupação tardia (somente no século XVIII) como a cartografia demorada têm relações diretas com as resistências das apropriações indígenas, das sociedades pré-coloniais, naquilo que se compreende como Ceará.

A ocupação tardia do Ceará, dialeticamente, era a existência/resistência de outro modo de vida (indígena), que tinha sua relação com a terra, com a natureza e entre eles mesmos bem diferente daquilo que seria trazido com a pecuária e a agricultura de subsistência para o mercado. Isto é, a propriedade privada, a divisão do trabalho entre proprietários e trabalhadores, a circulação do dinheiro, a apropriação desigual do produto do trabalho coletivo, a evangelização cristã da "alma", a ordem do falar somente em português e a maneira de passar a enxergar a natureza como recurso.

Francisco José Pinheiro (2007), em seu texto Mundos em confronto, diz que a compreensão da ocupação tardia do Ceará dá-se somente quando se analisa a formação desse território entre conflitos (indígena-lusitano) em conjunto com a formação territorial do litoral açucareiro.

Segundo o historiador,

na área açucareira, a conquista começou já no início do século XVI; enquanto que na região que se tornou lócus da pecuária, ela só aconteceu, para o mundo colonial, no final do século XVII e início do seguinte. Analisando as diferenças nos modos de vida, tendo na disputa pela terra a principal questão, é que vamos compreender o confronto entre nativos (indígenas) e lusitanos, em face do projeto de dominação portuguesa no Ceará. À medida que a produção açucareira avançava pelas terras do litoral, que se estendem da Paraíba até a Bahia, a pecuária, como uma atividade subsidiária da produção açucareira, foi sendo tangida para o interior. Dessa forma, ocorreu a ocupação do interior da região hoje denominada Nordeste, principalmente a dos territórios das capitanias da Paraíba, do Rio Grande do Norte e do Ceará. Esse espaço livre para os grupos indígenas, que haviam sido gradativamente expulsos da faixa litorânea, foi-se transformando aos poucos em territórios da pecuária. (Pinheiro, 2007, p. 17) 
A partir de Pinheiro (2007), cabe interpretar que durante o seiscentos, o setecentos e o oitocentos, o Ceará passaria por alguns pontos de inflexões contextuais no que se refere à forma-conteúdo da ocupação daquilo que passou a ser compreendido como território dessa província. Segundo o autor, entre 1654 a 1720, o Ceará esteve sob a predominância de territórios livres (diferentes apropriações indígenas em aldeias, nativos ou refugiados), sendo sua ocupação mais forte nas serras do Araripe, Apodi, Ibiapaba e nas margens de rios e vales, principalmente do Jaguaribe. O enfraquecimento desses territórios e do modo de vida deu-se por conta do processo de expansão da fronteira lusitana rumo ao interior, sendo marcantes os conflitos e o genocídio por parte dos portugueses, tendo, como o grande ato representativo, a Guerra dos Bárbaros, conflitos fragmentários que envolveram soldados, missionários, agentes da Coroa portuguesa e índios de nações diversas do interior do Norte do Brasil (Puntoni, 1998).

Entre 1720 e 1800-1840, permaneceu o Ceará na era de domínios territoriais baseados na pecuária, período que também carregaria os inícios da produção de algodão e outras ocupações territoriais nas serras. Essa ocupação, do século XVIII ao século XIX, também se daria, em sua predominância, nas antigas territorialidades indígenas, fortalecendo sua submissão, desterritorialização e reterritorialização em outras terras. E tudo isso, toda essa demora para ocupar o Ceará (na visão do europeu), ou dizendo de outra maneira, todo esse processo tardio de expansão da fronteira lusitana em face de outros pontos portugueses também retardou uma espécie de cartografia setecentista, necessária para ler as ocupações-conflitos existentes e representar (politicamente) o Ceará, para demarcar os recursos naturais e contar a população no processo da trágica prática civilizatória e genocida.

Segundo Clóvis Ramiro Jucá Neto (2010), essa ausência de uma cartografia setecentista fez com que os cosmógrafos da Corte interpretassem o Ceará pelo litoral, com completo desconhecimento do sertão, dos currais, dos caminhos, dos povoados fixados, criando a leitura ideológica senhorial da província como terra de índios selvagens. Para o autor, alguns instrumentos em tecnologias e outros investimentos econômicos não foram realizados no Ceará por falta dos "reais limites da territorialidade cearense e de suas possibilidades econômicas" (Jucá Neto, 2010, p. 2).

O que já nos cabe anunciar é que a formação da província do Ceará, no interior da região Norte e no conjunto do Estado territorial do Brasil, 
esteve de forma tardia e periférica no que se refere à sua importância para o mercado de exportação, a compra de braços de escravos e de outras mercadorias importadas e mesmo na participação política nas instituições etc, isto é, no topo da hierarquia das ordens nacionais e nos negócios com o capitalismo internacional. O que não quer dizer que não tínhamos escravos, produtos para exportação (interprovincial e internacional) ou consumo das mercadorias dos países que estavam no centro do capitalismo (Mello, 1999).

Na questão da cartografia, o que chamamos de Ceará é uma circunscrição da superfície terrestre demarcada ainda nos últimos anos da colonização portuguesa e aperfeiçoada durante os anos de constituição do Estado territorial, da classe senhorial e da monarquia no Brasil. Foi somente no século XIX, em 1817-1818, pelas mãos do engenheiro Antonio José da Silva Paulet e a pedido do governador da capitania Manoel Ignácio de Sampaio, que foi elaborada a carta do Ceará, que compõe o desenho não somente próximo do que era tido como o Ceará do século XIX, mas também quase idêntico ao que se tem como limites para os dias atuais.

Para Jucá Neto (2010), os trabalhos de Silva Paulet resultaram na elaboração da Carta Maritima e Geographica da Capitania do Ceará, acompanhada da Planta do Porto e Villa da Fortaleza na margem inferior direita, cidade para a qual o engenheiro havia projetado um plano em xadrez.

A carta de Paulet, de 1817-1818, criara não somente uma representação cartográfica para o Ceará, como acabaria por formar uma base para os desenhos futuros da província, com os interesses mais diversos possíveis, como as redes hidrográficas ou os caminhos aquáticos, os caminhos antigos de terra, a distribuição das vilas, a rede urbana e mesmo a classificação de cunho étnico, como cidades de brancos, índios ou de maioria negra.

A abertura legada pelo engenheiro, para nós, ainda estaria na criação simbólica de uma base territorial para a tardia representação política estatal (por homens enviados para serem governadores da capitania e, no Império, presidentes da província, ou mesmo para servir a atuações materiais das oligarquias locais) quer no interior da região Norte, quer no trâmite monárquico entre o Ceará e as centralidades políticas no Sul do Brasil. 
Mais precisamente, essa cartografia nos serviria para pensar o processo descentralizado ou, como o chamaremos, a centralidade dividida, que marca a especificidade da formação territorial do Ceará na região Norte do Brasil, junto com a província de Minas Gerais, para todo Estado territorial imperial (Mello, 1999).

A formação territorial do Ceará impulsionada pela comercialização, via centralidade dividida

Ao que nos é de interesse, no que se refere às aberturas para a demarcação/ ocupação de terras para uso ou poupança e suas ligações por caminhos aquáticos e terrestres, o próprio Jucá Neto (2007), elaborando reflexões em outro escrito, baseado no documento Vias de Communicação do Ceará Colonial, de Carlos Studart Filho (1937), busca compreender as estradas que faziam boiadeiros-boiadas se ligarem do Ceará com as províncias vizinhas da região Norte, alertando ser o conteúdo tardio do próprio Ceará a especificidade de se configurar (fixar e movimentar) como um território de passagem entre Pernambuco, Paraíba e Piauí.

O documento de Studart Filho (1937) aparece-nos como aquele que consegue fazer uma síntese do que foi a formação territorial interna do Ceará e a sua relação com a região Norte. Consegue, em grande valia, elaborar os trajetos dos principais caminhos antigos, formados a partir da ocupação europeia tardia, ou, como chama Jucá Neto (2007), das principais "estradas dos boiadeiros", permitindo-nos ler a centralidade dividida do comércio do Ceará, centralidade dividida posta e específica do território da província, que tinha suas relações político-econômicas mais acentuadas com as praças de Recife, São Luís e Belém, do que com a própria capital Fortaleza.

Entre os caminhos antigos, principais ou gerais, que nos permitem tais interpretações da ocupação e da centralidade dividida, nas descrições de Studart Filho (1937), estava sendo apresentada "a Estrada Velha, Estrada Geral do Jaguaribe, a Estrada Nova das Boiadas, a Estrada das Boiadas, a Estrada Camocim-Ibiapaba, a Estrada Crato Oeiras, a Estrada Crato Piancó” (Jucá Neto, 2007, p. 9). Esses caminhos costuravam o Ceará e o Norte do Brasil, ligavam nós de produção da lavoura e indicavam os caminhos onde se criavam e negociavam as creações, formando redes territoriais de tais comércios. 
Sobre a interpretação do documento de Studart Filho (1937) e os caminhos que as estradas iam tomando, tocando e conectando, torna-se melhor deixar o próprio Jucá Neto (2007, p. 9-11) dizer:

A Estrada Velha ligava Recife ao Maranhão pelo litoral [...] A Estrada Geral do Jaguaribe partia de Aracati, principal porto da Capitania, descia o rio Jaguaribe, passando por Russas e Icó. Foi a mais importante via de circulação do Ceará no século XVIII, por onde eram levadas as mercadorias para o sertão, vindas de Aracati, provenientes das demais capitanias. Em direção ao Aracati seguia toda a produção do vale do Jaguaribe que 'consistia quase unicamente em couros salgados e espichados e alguma pellica das que se trabalhavam em todo o sertão cearense' e as boiadas que seriam salgadas nas oficinas de charque no litoral, no espaço da vila aracatiense, e transportadas em embarcações para Recife, Salvador e Rio de Janeiro. Pelo rio Jaguaribe, Icó e Aracati - as duas principais vilas do Ceará no século XVIII - mantiveram um intenso comércio, inicialmente com o gado e posteriormente, no século XIX, com o algodão. A Estrada Nova das Boiadas ligava o vale do rio Acaraú, no Ceará, e o Piauí à Paraíba, pelo Ceará. Vindo da direção da Paraíba, passava por Pau-dos-Ferros, ultrapassava o rio Jaguaribe na altura da atual cidade de Jaguaribe, seguia pelo riacho do Sangue, cruzava o rio das Pedras, chegava ao rio Banabuiú e encontrava o rio Quixeramobim para alcançar a cidade de Quixeramobim. De lá, um ramal seguia para Crateús, entrando no Piauí pelo rio Poti. Outro ramal partia para Sobral seguindo para o porto de Acaraú, na bacia do rio Acaraú e em direção a Granja, rumo ao porto de Camocim, na bacia do rio Coreaú. Depois de Pau-dos-Ferros, no Rio Grande do Norte, encontrava a Estrada das Boiadas, na Paraíba, e seguia para a cidade de Recife [...] A Estrada das Boiadas vinha do médio Parnaíba em direção a Oeiras no Piauí; passava por Tauá, seguia o rio Jaguaribe até Icó, quando, alcançando a Paraíba, seguia por Souza, Pombal, Patos, Campina Grande, Ingá, Mogeiro e Itabaiana. De Itabaiana partia ou em direção a João Pessoa via Pilar e Santa Rita, ou em direção ao porto de Recife e Olinda, cruzando Pedra do Fogo, Itambé e por fim Goiana e Igarassu, em Pernambuco. De Tauá, podia-se alcançar a Estrada Nova das Boiadas. Pela Estrada das Boiadas eram abastecidos tanto os matadouros e as oficinas de charque do litoral, seguindo pela Estrada Geral em direção ao Aracati, como as feiras de gado em Campina Grande, Itabaiana, Pedra do Fogo e Itambé, na Paraíba, e Goiana e Igarassu, em Pernambuco. Dela também se serviam os fazendeiros do sertão para refazer seus gados, nas pastagens do rio Parnaíba, após as longas estiagens. A Estrada Camocim-Ibiapaba ligava Viçosa do Ceará, na serra da Ibiapaba, a Granja e ao porto de Camocim pela bacia do Coreaú. Quixeramobim interligava-se, ainda, com os sertões da atual Santa Quitéria pela Estrada da Caiçara. Do Crato, partia-se tanto para Oeiras - Estrada 
Crato-Oeiras - via Campos Sales e Picos pelos vales férteis do Araripe, como para Piancó - Estrada Crato-Piancó - alcançando Patos, na Estrada das Boiadas, já na Paraíba.

Cabe destacar, ainda, outra intersecção que foi se formando entre a pecuária e a construção das villas no Ceará, como também explica Jucá Neto (2007, p. 11-12):

Até os primeiros anos do século XIX, com exceção de Aquiraz (1713) e Fortaleza (1726), localizadas no litoral por questões de defesa, exceto as vilas fundadas a partir de antigos aldeamentos indígenas, as demais vilas criadas no território localizavam-se em pontos estratégicos para a circulação do gado nas estradas das boiadas. Falamos do Icó (1736), Aracati (1748), Sobral (1773), Quixeramobim (1789), Russas (1801) e Tauá (1802). A vila do Aracati foi o principal porto do Ceará, na foz do rio Jaguaribe, durante o século XVIII. Em seu espaço, localizavam-se as principais oficinas de charque do período. Antes mesmo da elevação à condição de vila, comercializava-se de 'vinte a vinte cinco mil bois' para a produção de carne seca [...] Icó foi o mais importante ponto de escoamento, no sertão, da produção cearense. Para a vila seguiam boiadas de todas as estradas e partiam outras tanto para o Aracati como para as feiras da Paraíba e de Pernambuco. Os fazendeiros localizados nas proximidades do Icó possuíam uma vantagem sobre os demais da Capitania do Ceará por estarem próximos das feiras de Pernambuco e da Paraíba [...] A ativação do comércio e o processo de centralização administrativa com a fundação das vilas criaram as bases para a futura rede urbana do território, alterando lentamente - no decorrer do século XVIII e início do século XIX, após o declínio da pecuária e já com os primeiros sinais da produção algodoeira, que deu sentido econômico à Província do Ceará durante o século XIX - o quadro de dispersão.

O que cabe compreender é que o movimento interno no Ceará, do século XVIII até 1800-1870 (na predominância dos territórios da pecuária), vai dar-se principalmente pelos "portos de Aracati, Acaraú e Camocim e, posteriormente, o de Fortaleza", que "constituiriam desde então, os centros de convergência regional", sendo que "os três primeiros portos concentravam o comércio da carne-seca ou as charqueadas", destacando-se as cidades de Aracati e Sobral, e aparecendo Fortaleza na cena apenas a partir de meados do século XIX, com o algodão e a exportação de café (Souza, 2005, p. 17).

E aqui, entre os anos de 1800 a 1870, parece existir mais um ponto de inflexão, além daqueles vistos anteriormente em Pinheiro (2007), e que 
estaria especificado na queda da importância da venda e da criação de gado no avançar do oitocentos, mesmo que essa atividade continuasse a ser importante; na construção de uma incipiente classe política senhorial local em Fortaleza; e na crescente produção de algodão e de café para exportação - produtos que eram até então especificamente para o mercado interno -, "abrindo" as possibilidades de articular-se diretamente com o capitalismo internacional, metamorfoseando as ocupações do território do Ceará. Toda essa articulação fez parte da travessia (sincrônica e diacrônica) entre um território herdado do "Ceará colônia" para um "território provincial monárquico", que iria se construindo, retrospectiva e particularmente, com mais força política e histórica no processo de construção da monarquia.

A formação territorial do Ceará impulsionada pelo processo de provincialização tardia

O ponto de inflexão entre 1800 a 1877 era exatamente este: o processo de provincialização tardia que se desenhava e que era buscado por alguns homens no Ceará. Esse processo de provincialização foi marcado pela tentativa de criar uma centralidade no território provincial a partir da construção da cidade/praça de Fortaleza, construção esta que dialogaria, no plano político-econômico, com a rivalidade da cidade/porto de Aracati, até então o principal centro do Ceará, como mostrado anteriormente, e que, em suma, se conectava mais com Pernambuco e com o Rio Grande do Norte do que com a própria capital (Mello, 1999).

A formação dos principais caminhos de terra descentralizados no Ceará, principalmente no que se refere ao rumo da capital, eram rebatimentos internos do poder que outras províncias vizinhas tinham no território do Ceará. O controle estava tanto nos portos do litoral (como Aracati e Acaraú) quanto no sertão, na produção da lavoura e criação do gado, que fazia circular os produtos pelas trilhas de terra. O contexto da produção para o mercado externo de café e principalmente de algodão, que vai crescer durante o oitocentos, passa a fortalecer a tentativa de construir Fortaleza como praça principal do Ceará, tentativa que teria como rival Aracati e as outras províncias.

A produção de algodão e de café no Ceará, por exemplo, entre 1850 a 1870 realizou-se, na verdade, como uma primeira fase de ascensão desses produtos com relação à pecuária e agitou os proprietários, os homens 
de letras no Ceará, os homens de províncias vizinhas e o estado provincial para as condições dos transportes, dos portos e de todos os instrumentos que melhorassem, barateassem e ampliassem a produção de algodão e de café para o mercado de exportação interprovincial e internacional (Tabela 1).

TABELA 1 - Exportação de algodão e de café em Fortaleza (1850/1870)

\begin{tabular}{|c|c|c|}
\hline \multirow{2}{*}{ Anos } & \multicolumn{2}{|c|}{ Quilos } \\
\cline { 2 - 3 } & Algodão & Café \\
\hline 1850 & 717.293 & 207.909 \\
\hline 1851 & 630.337 & 218.938 \\
\hline 1852 & 991.628 & 442.192 \\
\hline 1853 & 746.915 & 366.621 \\
\hline 1854 & 703.303 & 101.083 \\
\hline 1855 & 954.062 & 128.810 \\
\hline 1856 & 904.334 & 83.930 \\
\hline 1857 & 1.128 .168 & 510.924 \\
\hline 1858 & 1.091 .375 & 575.926 \\
\hline 1859 & 1.139 .354 & 828.730 \\
\hline 1860 & 863.479 & 1.293 .300 \\
\hline 1861 & 745.828 & 2.810 .940 \\
\hline 1862 & 646.050 & 2.157 .546 \\
\hline 1863 & 888.290 & 1.605 .651 \\
\hline 1864 & 1.403 .261 & 454.280 \\
\hline 1865 & 2.002 .114 & 1.092 .344 \\
\hline 1866 & 2.380 .838 & 778.604 \\
\hline 1867 & 4.332 .412 & 1.812 .687 \\
\hline 1868 & 4.686 .300 & 50.800 \\
\hline 1869 & 5.219 .147 & 877.523 \\
\hline 1870 & 7.253 .893 & 560.283 \\
\hline
\end{tabular}

Fonte: Guabiraba (1989), dados adaptados pelo autor.

O fato é que no Ceará vai existir o aumento da produção de algodão e café, cuja circulação dos produtos era realizada pelos caminhos antigos, tendo como base a centralidade dividida do território que, conectando diversidades de pontos produtivos, vai passar a alcançar os "trapiches" mais próximos, provocando e acentuando, além da divisão territorial, a rivalidade entre os produtores dos diversos lugares. 
A interpretação genérica que temos até agora para explicar o crescimento dos números da produção de algodão e café para exportação apresentados na Tabela 1 - principalmente o fato de a produção do algodão registrada em 1869 ser quatro vezes maior que no início da década de 1850 e de o café ter apresentado aumento e queda do durante essas duas décadas - está tanto na valorização que esses produtos ganharam no mercado mundial francês e principalmente no inglês, quanto nas consequências de um acontecimento externo anterior, a Guerra de Secessão norte-americana (1861-1865). Esse conflito inviabilizaria o monopólio de troca entre o Império Britânico e a antiga colônia inglesa, que crescia a todo vapor no oitocentos, isto, pelo menos, para explicar o crescimento produtivo até 1869, que acabou por anexar o Ceará ao mercado externo em meados de oitocentos (Leite, 1994) .

Os dados ainda representam uma afirmativa que caminha próximo à interpretação de Evaldo Cabral de Mello (1999), que diz ser esse período um momento do tráfico interprovincial de escravos, de venda dos braços que plantavam, colhiam e faziam a classe senhorial ser os proprietários que eram. A lógica seria que a produção caísse e o Norte fosse à falência, mas "apesar do tráfico interprovincial [de escravos], o volume físico da produção agrícola das províncias setentrionais continuavam a crescer nesses anos do Império" (Mello, 1999, p. 32).

E para o Ceará, a Guerra de Secessão norte-americana havia mesmo aberto os mercados dos produtores da lavoura aos ingleses, que também procurariam outras fontes de matérias-primas, como era o caso da Índia (sua colônia). No contexto da escala monárquica, o historiador Eric Hobsbawm (2003) diz que essa foi a primeira vez que o Brasil salvou a Inglaterra, não deixando faltar a matéria-prima de que necessitavam os ingleses para a indústria têxtil. E não apenas o Ceará, mas também a Paraíba, o Rio Grande do Norte e províncias do Sul estariam envolvidas nessas trocas.

Mesmo após ser restabelecido o controle político e o retorno à atividade produtiva algodoeira nos Estados Unidos, o Ceará havia construído, durante a década de 1860, um anúncio para o exterior de que aqui se produziam algodão e café, e havia casas de comerciantes e especuladores locais, imperiais e estrangeiros (portugueses, franceses, ingleses etc.).

Especificando o mercado e a entrada de casas francesas nas negociações, Denise Monteiro Takeya (1995, p. 136) comprova o sinal negociador que a década cafezal-algodoeira de 1860 havia passado para o mundo do capital: 
Aos anos de 1860 correspondeu uma fase de expansão econômica alicerçada na agro-exportação, como o Ceará até então não conhecera. Sobre essa produção foram produzidas notícias, pelos agentes consulares, dirigidas a comerciantes franceses, estimulando-os a estabelecerem casas comerciais na província. O crescimento da economia cearense nesse período significava, para esses interesses, a possibilidade de atuarem não só no ramo da exportação de matérias-primas para a Europa, mas também no ramo da importação de manufaturas francesas. Com efeito, como decorrência do processo de integração da economia cearense à divisão internacional do trabalho, a riqueza aí gerada potencializava uma parcela da população, ainda que restrita, como mercado consumidor dos artigos franceses, sobretudo aqueles de luxo, que tão especialmente os caracterizavam.

Além dessa análise, a autora vai enumerar uma quantidade de "casas estrangeiras" comerciais francesas que começam a se instalar em Fortaleza entre 1860 e 1870, como também em Aracati e Sobral. Essas casas, como bem explica Takeya (1995), não estariam voltadas apenas para as negociações de algodão, entrando também em outras negociações, como a compra do couro para exportação, a montagem de revendedoras de farinha de trigo e de centros de venda de "fazendas" de pano. ${ }^{5}$

É nessa intersecção entre formação da classe senhorial no Brasil, formada por produtores de algodão e de café, e a conexão internacional do Ceará no mercado exterior que vai ser gerada a problemática dos caminhos internos, a vontade dos homens do Ceará de se inserir na era ferroviária do período monárquico e comprar máquinas que fizessem das rotas comerciais algo mais lucrativo (Camelo Filho, 2000).

O subcontexto que se construía entre a década de 1850 a 1870 no Ceará desenhava questões e debates que pautavam um número infinito de problemas, comuns a todas as províncias do Estado territorial monárquico. Dentre eles, destacavam-se as exigências das classes senhoriais por meios de transporte e comunicação que atuassem como forças produtivas e estímulos e instrumentos para aumentar a produção da lavoura (escravização da natureza) ou para expandir a produção que já existia e que chegava ao litoral por muitos caminhos defeituosos.

A herança da centralidade dividida territorial do Ceará - representada, em uma de suas dimensões, pelos caminhos antigos, expressos pela leitura de Studart Filho (1937), com a formação de diferentes núcleos produtivos no sertão, centros urbanos e cidades portuárias - estaria a 
partir de 1850 sendo o foco de debates para exigir projetos ferroviários que passassem a ligar os portos às portas das propriedades do interior da província.

Assim, os pedidos de implantação de ferrovias no Ceará estavam, além de tudo, nas intersecções de contextos que, de um lado, eram expressos pela formação específica do território do Ceará, quer como periferia na região Norte, quer como recém-convidado para participar do mercado exterior, e de outro, pela burocracia e dependência de recursos financeiros do Estado, dimensão que dependeria daquelas relações de trocas de favor, dos contatos políticos e científicos com o Sul, ou mesmo dos interesses das empresas britânicas em construir estradas de ferro no Ceará (Assis, 2011).

Entre os anos de 1864 a 1877, foram sendo anunciados para o Ceará, pelo menos, quatro projetos ferroviários. São eles: 1) Projeto Fortaleza-Pacatuba-Baturité-Crato (1864); 2) Projeto Mundaú-Itapipoca-Imperatriz (1865); 3) Projeto Aracati-Icó-Crato (1873); 4) Projeto Acaraú-Sobral-Ipu (1873) (Assis, 2011).

Os projetos ferroviários ora sugeriam a abertura de estradas novas - propostas de mecanização do território -, ora eram intentos de modernização dos caminhos antigos, isto é, projetos que propunham inserir máquinas nos traçados de alguns caminhos já definidos desde os tempos coloniais, rompendo, assim, o tempo natural das relações entre os lugares (Santos; Silveira, 2006). Aqui, o grande debate interno é que a classe senhorial de Fortaleza fez de tudo para ter, de um lado, seu projeto ferroviário realizado e de outro, para criar os obstáculos para a aprovação dos restantes dos projetos, principalmente, o Projeto Aracati-Icó-Crato.

O Projeto Fortaleza-Pacatuba-Baturité-Crato, anunciado em 1864, elaborava no papel aquilo que era o pensamento e o planejamento territorial da província, por parte da classe senhorial de Fortaleza, isto é, estava sendo pensada uma via férrea que possibilitasse a ampliação da acumulação, o aproveitamento, as valorizações e a exploração das terras privadas (e férteis) e a exploração do trabalho nos sertões e nas serras. A centralização em Fortaleza era o grande trunfo que a garantiria como capital e centro econômico principal, pois pretendia modernizar-se antes das demais, com o apoio do Sul do Brasil e com os recursos públicosprivados-estrangeiros nas negociações no interior da província e com a própria Corte. Essa ferrovia apresentava-se como a proposta de um 
caminho novo, que rompia com uma certa herança colonial material do Ceará (Assis, 2011; Mello, 1999).

O Projeto Ferroviário Mundaú-Itapipoca-Imperatriz, de 1865, que foi apresentado inicialmente como um projeto de estrada de terra em 1859, entrou no debate em busca do cavalo mecânico, a partir do início da Guerra de Secessão norte-americana (1861-1865), da expansão das plantações de algodão nas faldas e nas margens da situação geográfica na qual se encontrava essa serra (Imperatriz), bem mais próxima ao litoral (porto de Mundaú) que muitos outros lugares em que se produzia algodão, como o caso de Icó e de grande parte do Valle do Jaguaribe (Assis, 2011).

Já o projeto Aracati-Icó-Crato, de 1872-1873, diferentemente dos projetos Fortaleza-Pacatuba-Baturité e Mundaú-Itapipoca-Imperatriz, foi um pedido ferroviário que iria ser produzido sobre um corredor espacial formado desde os tempos dos domínios portugueses. Na verdade, esse corredor entre Aracati-Icó foi o mais movimentado da província, formador de diversos currais, fazendas, vilas e cidades ao longo da estrada principal. Seguindo o leito do rio Jaguaribe, o corredor acabava por articular o litoral com Icó, cidade configurada territorialmente como o maior entreposto, e ligava a província, no lado ocidental, ao Piauí; ao sul, a Crato e Pernambuco, e ao oriente, à Paraíba e ao Rio Grande do Norte. Além disso, Icó também era o ponto de encontro dos povoados do centro do sertão, como Quixeramobim e Quixadá.

Segundo Evaldo Cabral de Mello (1999), o projeto ferroviário Aracati-Icó-Crato não era um mero pedido de concessão ferroviária, e sim o alimento para a rivalidade que existia entre os que negociavam em Aracati e os que negociavam em Fortaleza. Essa disputa era a própria comprovação da tese da centralidade dividida no Ceará, de formações espaciais com temporalidades diferentes e com articulações desiguais, em que a autonomia estava, em grande parte, em Recife, ou mesmo com as casas estrangeiras, e não com Aracati.

O último projeto, o plano ferroviário de 1873 para ligar o porto de Acaraú à cidade de Sobral e à serra do Ipu, também estaria sobre a rota de circulação antiga, configuração herdada da centralidade dividida do Ceará, que fazia redes distintas em cada porto (Assis, 2011).

E esse trajeto também nos é instigante pelas diferenças que estabelece com os demais. A interpretação elaborada por Maria Auxiliadora Lemenhe (1991) para a província do Ceará considera que a expansão geo- 
gráfica sobre os fundos territoriais herdados da colonização e a articulação com o sertão, a partir de meados do oitocentos, está mais para oeste e para o centro, do que para o leste (corredor Aracati). É como se, por esse trajeto (centro-oeste), existisse um controle de Fortaleza sobre os portos, que não interferiria na acumulação, ou mesmo na hegemonia.

O que nos parece é que alguns pontos do sertão que não eram ocupados anteriormente pela cultura do algodão ou do café, como era o caso da serra da Meruoca, Ipu, Baturité, Maranguape e todos os pontos novos, passaram a ser controlados pela própria hierarquia já construída por Fortaleza, diferentemente do corredor antigo de Aracati, já inexorável, com Recife.

No conjunto dos quatro projetos de modernização, apenas o Fortaleza-Pacatuba-Baturité-Crato, no início da década de 1870, havia começado a se realizar materialmente, desbancando o seu grande rival, o projeto Aracati-Icó-Crato, principal rota formada no período da colonização portuguesa, sendo ainda esse traçado, para a província do Ceará, o caminho geomorfologicamente mais plano, com circulação mais rápida entre os lugares, além de ser uma das vias pelas quais entrava e saía a maioria dos produtos que circulava no mercado externo, no período da monarquia (Mello, 1999).

Como bem expõe Evaldo Cabral de Mello (1999, p. 224-225):

No intuito de arrebatar ao Aracati o comércio do Jaguaribe e do Cariri, ela [Fortaleza] sabotou quanto pôde o projeto da estrada Aracati-Icó. Em 1873, a Assembleia provincial chegou mesmo a engavetar o projeto de lei que autorizava a construção da linha; no ano seguinte, o agente consular da Grã-Bretanha no Aracati informava que o privilégio fora finalmente concedido, mas a 'três cavalheiros do Ceará [isto é, de Fortaleza], os quais, sendo os maiores acionistas da linha [Fortaleza]-Baturité, tem todo interesse em manter o assunto longe da atenção pública'. É que esses senhores [...] sabiam perfeitamente que a linha ‘Aracati-Icó-Crato' é muito mais importante e de maior interesse, com um futuro maior e mais seguro devido ao já considerável comércio com o interior, do que a estrada Ceará-Baturité. Afinal, em 1878, Fortaleza assestou o golpe definitivo nas aspirações ferroviárias do Aracati.

O processo de provincialização tardia, uma tentativa de autonomização e hegemonia de uma praça no Ceará (neste caso, em Fortaleza), vai passar a ser o próprio processo de centralização dos negócios, decisões políticas e relações com os consumos exteriores, a partir da hierarquia 
da capital da província, e não mais de Aracati. E tudo isso contribuiu, em parte, para a implantação da ferrovia Fortaleza-Pacatuba-Baturité-Crato, que consolidou a hegemonia que vinha sendo construída em Fortaleza, no Segundo Reinado, pela oligarquia Pompeu, a partir da figura do senador Pompeu, artífice do poder imperial, da classe senhorial e da ciência moderna (Sousa Neto, 1997).

A produção da organização do espaço do Ceará, a partir da implantação de uma estrada de ferro "segura" entre Fortaleza e o interior, a captura do comércio de serras e sertões, o poder de uma classe senhorial em formação, comandada pelo senador Pompeu, controlando o crescimento dos negócios da lavoura de algodão e de café para a exportação, os rebatimentos agroexportadores da Guerra de Secessão norte-americana (1861-1864), o empréstimo pelo governo provincial-central de capital para investir na estrada de ferro, a queda da produção da lavoura na seca de 1877 e o uso dessa estiagem para a venda da ferrovia Baturité para o Governo Imperial, que deu continuação às obras, são os resumos generalizados que vão fazer de Fortaleza-Pacatuba-Baturité-Crato a única ferrovia a ser construída e que vai consolidar Fortaleza como centro hegemônico do Ceará, desconstruindo, no processo, o qualitativo de centralidade dividida herdada da colonização (Assis, 2011, 2010).

\section{Palavras finais}

Em suma, o que estava em conflito era o domínio do espaço geográfico, a transformação daquela base territorial dividida, herdada da colonização, para a construção de uma centralidade geográfica, com o objetivo de controlar a circulação de produtos, do trabalho e das informações.

Esta breve análise do Ceará, via transformação territorial, é uma resposta geográfica de como o poder hegemônico acabou por produzi-lo sob certas visões contextualizadas de mundo, configurando-o sob as ambições que realizariam os planos entre as classes senhoriais dos lugares e o centro do capitalismo.

Nesta esteira, a análise da formação dos caminhos internos possibilita-nos interpretar a formação territorial das províncias e do Estado territorial monárquico e, dialeticamente, entender que essas pretensões estão internalizadas em uma totalidade multiescalar, que tem como essência as exigências do sistema mundo moderno-colonial (Mignolo, 2005). 


\section{Notas}

1. Até o ano de 1799, o Ceará era uma capitania (nome dado pela metrópole portuguesa aos recortes administrativos e políticos na colonização) anexada a Pernambuco, sendo que era dessa centralidade econômica e escravista que partiam os mandos políticos, as proximidades com os criadores, as ocupações territoriais e as mais frequentes relações comerciais. Sobre esse assunto, ver: Girão (2000), principalmente o Capítulo VI, Separação de Pernambuco, p. 173-191.

2. O Norte Agrário, para Evaldo de Mello (1999), eram as províncias de Pernambuco e da Bahia, territórios que estavam ou estiveram envolvidos como um dos principais centros mercantis e escravistas da Monarquia. Na interpretação do autor, províncias como o Ceará, Paraíba e Rio Grande do Norte fizeram parte do Velho Norte, territórios que pouco dependeram dos braços de escravos e que também pouco sentia a falta de braços.

3. Torna-se aqui necessário fazer a ligação entre o conceito de região como produto social, elaborado por Ilmar de Mattos (1999), com a inseparabilidade entre produção para subsistência e mercado interno, e produção para o mercado externo e a formação da centralidade regional. Para detalhes, ver Carvalho Franco (1997).

4. Para Caio Prado Júnior (1978), o século XVIII é fundante para a ocupação da margem ao norte do rio São Francisco. O historiador econômico destaca a pecuária como a grande responsável pela ocupação do interior da região Norte (que, retrospectivamente, já é chamada em seu texto de Nordeste), constituindo essa atividade, criadora e industriosa, uma formação econômica e social regional específica. Baseada no isolamento, na ocupação e fixação às bordas dos rios e no processo de reprodução social, grosseiramente, a pecuária na região sertaneja Norte esteve mais envolvida com o trabalho livre e doméstico do que com o trabalho escravo, sendo, porém, imprescindível para os abastecimentos dos braços negros que, explorado na terra de produtos para o mercado externo, pouca alimentação se produzia ou se objetivava produzir, já que trazer dos outros interiores era bem mais em conta. Ver: Prado Junior (1978), especificamente o Capítulo III, Expansão da Colonização.

5. Entre algumas das casas instaladas durante as décadas de 1860 e 1870 destacam-se: D. M Takeya (1995); Kalkmann \& Cia (1867), que comprava couros para exportação; Brunn \& Cia; J. Schaepffer \& Cia (1874), que vendia trigo; Jeanvenand \& Cia, que importava e vendia fazendas de panos aos comerciantes do Norte e, principalmente, as casas da família Boris Frères, franceses que espalhariam lojas nas principais cidades do Ceará (Takeya, 1995, p. 136-157).

\section{Referências}

ASSIS, R. J. S. de. Ferrovias de papel: projetos de domínios territoriais no Ceará (1864-1880). Dissertação (Mestrado em Geografia) - Centro de Ciências, Universidade Federal do Ceará, Fortaleza, 2011. 
ASSIS, R. J. S. de; FURTADO SAMPAIO, J. L. Pensamento geográfico das secas, dos trilhos e dos braços: ferrovia Baturité (1870-1889). Mercator - Mercato de Geografia da UFC, v. 9, n. 19, maio-ago. p. 77-86, 2010.

CAMELO FILHO, J. V. A implantação e consolidação das estradas de ferro no Nordeste Brasileiro. Tese (Doutorado em Economia) - Instituto de Economia, Universidade Estadual de Campinas, Campinas, SP, 2000.

CARVALHO FRANCO, M. S. de. Homens livres na ordem escravocrata. 4. ed. São Paulo: Unesp, 1997.

GIRÃO, R. História econômica do Ceará. Fortaleza: Programa Editorial Caso José de Alencar, 2000.

GUABIRABA, C. Ceará: A crise permanente do modelo exportador, 1850-1930. Fortaleza: Instituto da Memória do Povo Cearense, 1989.

HOBSBAWM, E. Da Revolução Industrial Inglesa ao Imperialismo. 5. ed. Rio de Janeiro: Forense Universitária, 2003.

JUCÁ NETO, C. R. Desenhando o Ceará. $3^{\circ}$ Simpósio de Iberoamericano da História da Cartografia. Anais... São Paulo, Universidade de São Paulo, 2010. p. 1-20.

JUCÁ NETO, C. R. Vilas, Povoados e Estradas do Ceará Colonial: os caminhos da ocupação territorial. X Simpósio de Geografia Urbana. Anais... Florianópolis, 2007.

LEITE, A. C. O algodão no Ceará: estrutura fundiária e capital comercial no Ceará (1850-1880). Fortaleza: Secretaria da Cultura e Desporto do Ceará, 1994.

LEMENHE, M. A. As razões de uma Cidade: Fortaleza em questão. Fortaleza: Stylus Comunicações, 1991.

MATTOS, I. R. O tempo Saquarema: a formação do Estado Imperial. São Paulo: ACCESS, 1999. 285 p.

MELLO, E. C. de. O Norte Agrário e o Império (1871-1889). 2. ed. Rio de Janeiro: Topbooks, 1999.

MIGNOLO, W. A colonialidade de cabo a rabo: o hemisfério ocidental no horizonte conceitual da modernidade. In: LANDER, E. A colonialidade do saber: eurocentrismo e ciências sociais. Buenos Aires: Clacso, 2005. p. 71-103.

PINHEIRO, F. Mundos em confronto: povos nativos e europeus na disputa pelo território. In: SOUZA, S. Uma nova história do Ceará. 4. ed. Fortaleza: Demócrito Rocha, 2007. p. 17-55.

PRADO JUNIOR, C. História econômica do Brasil. 21. ed. São Paulo: Brasiliense, 1978.

PUNTONI, P. A Guerra dos Bárbaros: povos indígenas e a colonização do sertão nordeste no Brasil (1650-1720). São Paulo: Edusp/Hucitec, 1998.

SANTOS, M.; SILVEIRA, M. L. O Brasil: território e sociedade no início do século XXI. 9. ed. Rio de Janeiro: Record, 2006. 
SOUZA, M. S. de. Ceará: bases de fixação do povoamento e crescimento das cidades. In: SILVA, J. B.; CAVALCANTE, T. C.; DANTAS, E. W. C. Ceará: um novo olhar geográfico. Fortaleza: Demócrito Rocha, 2005. p. 13-31.

SOUSA NETO, M. F. Senador Pompeu: um geógrafo do poder no Império do Brasil. Dissertação (Mestrado em Geografia Humana) - Universidade de São Paulo, São Paulo, 1997. 120 p.

STUDART FILHO, C. Vias de Communicação do Ceará Colonial. Revista do Instituto do Ceará, Fortaleza, p. 1-33, 1937.

TAKEYA, D. M. Europa, França e Ceará. São Paulo: Hucitec, 1995.

Raimundo Jucier Sousa de Assis - Doutorando em Geografia Humana pela Universidade de São Paulo Professor substituto da Universidade Estadual do Ceará.

José Levi Furtado Sampaio - Doutor em Geografia pela Universidade de São Paulo - Pós-doutor pela Universidade Federal da Bahia - Professor da Universidade Federal do Ceará.

Recebido para publicação em maio de 2012 Aceito para publicação em setembro de 2012 